\title{
Annually repeated influenza vaccination improves humoral responses to several influenza virus strains in healthy elderly
}

\author{
Iris A. de Bruijn* I, Edmond J. Remarque*, Walter E. Ph. Beyert,
} Saskia le Cessie $\ddagger$, Nic Masurel† and Gerard J. Ligthart* $\S$

The benefit of annually repeated influenza vaccination on antibody formation is still under debate. In this study the effect of annually repeated influenza vaccination on haemagglutination inhibiting (HI) antibody formation in the elderly is investigated. Between 1990 and 1993 healthy young and elderly, both selected by the SENIEUR protocol, were vaccinated consecutively with commercially available influenza vaccines. The elderly had a lower HI antibody response after one vaccination as compared to the young against the A/Taiwan/1/86 (HINI), B/Yamagata/16/88 and B/Panama/45/90 strains. Annually repeated vaccination did not result in a decrease of the HI antibody titres against the $A$ and $B$ vaccine strains in both age groups. Moreover, the elderly had a sigificantly higher HI titre against the $B$ strains after the second vaccination as compared to the first, resulting in comparable HI titres for young and elderly. Thus, annually repeated vaccination has a beneficial effect on the antibody titre against influenza virus and can contribute to a better antibody-response in the elderly. (c) 1997 Elsevier Science Ltd.

Keywords: annual influenza vaccination, HI antibody, SinIfUR elderly

In many countries annual vaccination against influenza is recommended for the elderly and the chronically ill', as it reduces influenza-associated morbidity and mortality in these groups $^{2+}$. Because the antigenic make-up of the influenza virus changes frequently and antibody titres may decline to non-protective levels within a year after vaccination, annual vaccination seems needed.

However, there are conflicting data on the benefit of annually repeated influenza vaccination and little is known about repeated vaccination in the elderly over 75 years of age. Hoskins et al. ${ }^{h}$ found a decreased protection in boys at a boarding school that had been vaccinated annually in comparison with boys that had been vaccinated only once. In some studies postvaccination serum haemagglutination inhibiting (HI)

\footnotetext{
*Section of Gerontology, University of Leiden, P. O. Box 9600,2300 RC Leiden, The Netherlands. TWHO Influenza Centre, Erasmus University Rotterdam, Rotterdam, The Netherlands. ‡Department of Medical Statistics, University of Leiden, Leiden, The Netherlands. §Present address: Section of Geriatrics, University Hospital of the Free University Amsterdam, Amsterdam, The Netherlands. TAuthor to whom all correspondence should be addressed. (Received 10 April 1996; revised version received 21 November 1996; accepted 10 January 1997)
}

antibody levels were similar in previously vaccinated and unvaccinated subjects ${ }^{7-10}$, whereas other studies showed significantly lower antibody responses in previously vaccinated subjects ${ }^{11.12}$

Studies on annually repeated influenza vaccination were often performed in children and young adults $^{7.13 .14}$, but influenza epidemics have the greatest morbidity and mortality in the elderly ${ }^{15}$, not only in those with underlying disease but also in apparently healthy subjects ${ }^{16-18}$. Underlying disease ${ }^{8,14}$, use of drugs and ageing in itself influences the immune response to influenza ${ }^{20,21}$ and progressive discases or deterioration can bias longitudinal studies. Therefore we measured the $\mathrm{HI}$ antibody titre for 4 years of annually repeated influenza vaccination in optimally healthy young and elderly who fulfilled the SENIEUR criteria ${ }^{22}$ throughout the study.

\section{MATERIALS AND METHODS}

\section{Subjects}

Between 1990 and 1993 young and clderly persons volunteered to receive an annual influenza vaccination, with new volunteers entering the study each year. Both age groups were selected according to the Senieur 
protocol 22 , by which strict admission criteria for immunogerontological studies in man are established. The protocol is based on clinical and laboratory data and it sets limits to pharmacological interference and discase influences. Elderly subjects mecting the SENIEUR criteria will hereafter be named SL:NILURS and the young Junisurs. The numbers and demographies of the volunteers are listed in Table 1 . All the SENII:UR subjects were independently living in the city of Leiden, the Netherlands. All the Junitur voluntecrs were students or laboratory staff in the city of Leiden, the Netherlands. All subjects gave informed consent and the study was approved by the Medical Ethics Comimittee of Leiden University.

To minimize biases which usually lead to an underestimation of the immune response in the elderly, the study was performed according to the criteria formulated by Beyer et al. ${ }^{23}$. Subjects with previous influenza vaccinations in the 2 years preceeding the study were excluded. Priming differences were taken into account in the interpretation of the data and a statistical correction for prevaccination titre was applied where appropriate.

\section{Vaccines}

Throughout the study commercially available vaccines according to WHO recommendations were used (Influvac ${ }^{\text {:" }}$, Solvay Duphar b.v., Weesp, The Netherlands) (Table I). For the 1990-1991 season a whole virus vaccine was used, containing $15 \mu \mathrm{g}$ haemagglutinin for the $A$ strains A/Taiwan/1/86 (H1N1) and A/Guizhou/54/89 (H3N2) and 10 $\mu \mathrm{g}$ haemagglutinin for the $B$ strains $B /$ Beijing/1/87 and $B /$ Yamagata/16/88. For the seasons $1991-1992$ and 1992-1993 subunit virus vaccines were used containing $15 \mu \mathrm{g}$ hacmagglutinin for each strain. In 1991 the vaccine contained the $\mathrm{A}$ strains $\mathrm{A} / \mathrm{Taiwan} / 1 / 86$ (H1N1) and $A / B e i j i n g / 353 / 89$ (H3N2) and the $B$ strains $\mathrm{B} / \mathrm{Be}$ ijing/1/87 and $\mathrm{B} / \mathrm{Panama} / 45 / 90$. In the $1992-1993$ season the vaccine consisted of the strains A/Taiwan/ $1 / 86 \quad(\mathrm{H} 1 \mathrm{NI}) \quad \mathrm{A} /$ Beijing/353/89 (H3N2) and $\mathrm{B} / \mathrm{Y}$ amagata/16/88. In the 1993-1994 season, only Senieurs were vaccinated. The vaccine contained the strains A/Taiwan/1/86 (H1N1), A/Beijing/32/92 (H3N2) and B/Panama/45/90.

\section{Serological analysis}

Haemagglutination inhibition titres were assessed in scra obtained prior to and 21 days after vaccination. HI antibody titres were determined following standard procedures using chicken erythrocytes and four HA-units of the virus ${ }^{2+}$. Influenza B strains were ether treated $^{25}$. Pre- and postvaccination sera were titrated simultancously and the sera were analysed in duplicate for antibody against all vaccine strains. HI tests were performed at the WHO National Influenza Centre for the Netherlands

Serological protection rates were calculated to extrapolate the HI titre to a measure of protection. In accordance to the $\mathrm{HI}$ test used, a titre of $100 \mathrm{U}$ was taken as a protective level for the influenza $A$ strains $^{2+26}$ and a titre of 200 for the influenza $B$ strains $^{2 t}$.

\section{Statistical analysis}

All calculations were performed on ' $\log$-transformed data. Mcan HI titres are displayed as geometric mean titres (GMT). All statistical procedures were performed with SPSS $^{\mathrm{TM}}$ for Windows ${ }^{\mathrm{TM}}$ v. 6.1 (SPSS inc.. Chicago, USA). Increase of GMT HI antibody after the first vaccination was analysed with the paired Student's $t$-test. Differences between Junieur and SENIEUR subjects after the first vaccination regarding the prevaccination titre were analysed with analysis of variance (ANOVA). Postvaccination titres were analysed with analysis of covariance (ANCOVA) with postvaccination titre as the dependent variable and prevaccination titre as the covariate. Where appropriate, an adjustment for the prevaccination titre was applicd.

To investigate the longitudinal changes in prevaccination and postvaccination titres after repeated vaccination, pairwise comparison of the SENIEUR and JUNIEUR pre- and postvaccination titres of two consecutive years was performed with the paired Student's $t$-test. The differences of pre- and postvaccination titres

Vaccination of subjects

\begin{tabular}{|c|c|c|c|c|}
\hline & \multicolumn{4}{|c|}{ Year of vaccination: $N$ (mean age \pm S.D.) } \\
\hline & 1990 & 1991 & 1992 & 1993 \\
\hline JUNIEURS & $43(22 \pm 3)$ & $18(22 \pm 2)$ & $9(22 \pm 2)$ & \\
\hline SENIEURS & $57(80 \pm 3)$ & $40(79 \pm 3)$ & $26(77 \pm 3)$ & $12(77 \pm 3)$ \\
\hline JUNIEURS & & $42(23 \pm 5)$ & $14(23 \pm 4)$ & \\
\hline Senieurs & & $55(79 \pm 3)$ & $28(79 \pm 3)$ & $17(78 \pm 2)$ \\
\hline JUNIEURS & & & $38(22 \pm 4)$ & \\
\hline & Vaccine strain & & & \\
\hline $\mathrm{H} 1 \mathrm{~N} 1$ & $\begin{array}{l}\text { A/Taiwan/1/86 } \\
(15 \mu \mathrm{g} \mathrm{HA})\end{array}$ & $\begin{array}{l}\text { A/Taiwan/1/86 } \\
(15 \mu \mathrm{g} \mathrm{HA})\end{array}$ & $\begin{array}{l}\text { A/Taiwan/1/86 } \\
(15 \mu \mathrm{g} \mathrm{HA})\end{array}$ & $\begin{array}{l}\text { A/Taiwan/1/86 } \\
(15 \mu \mathrm{g} \mathrm{HA})\end{array}$ \\
\hline $\mathrm{H} 3 \mathrm{~N} 2$ & $\begin{array}{l}\text { A/Guizhou/54/89 } \\
(15 \mu \mathrm{g} \mathrm{HA})\end{array}$ & $\begin{array}{l}\text { A/Beijing/353/89 } \\
(15 \mu \mathrm{g} \mathrm{HA})\end{array}$ & $\begin{array}{l}\text { A/Beijing/353/89 } \\
(15 \mu \mathrm{g} \mathrm{HA})\end{array}$ & $\begin{array}{l}\text { A/Beijing/32/92 } \\
(15 \mu \mathrm{g} \mathrm{HA})\end{array}$ \\
\hline B1 & $\begin{array}{l}\text { B/Yamagata/16/88 } \\
(10 \neq \mathrm{g} \mathrm{HA})\end{array}$ & $\begin{array}{l}\text { B/Panama/45/90 } \\
(15 / / \mathrm{g} \mathrm{HA})\end{array}$ & $\begin{array}{l}\text { B/Yamagata/16/88 } \\
(15 \mu \mathrm{g} \mathrm{HA})\end{array}$ & $\begin{array}{l}\text { B/Panama/45/90 } \\
(15 \text { ug HA) }\end{array}$ \\
\hline $\mathrm{B} 2$ & $\begin{array}{l}\text { B/Beijing } / 1 / 87 \\
(10 \mu \mathrm{g} \mathrm{HA})\end{array}$ & $\begin{array}{l}\text { B/Beijing/1/87 } \\
(15 / \mathrm{g} \mathrm{HA})\end{array}$ & & \\
\hline
\end{tabular}


between Senieur and Junieur subjects after repeated vaccination were evaluated with the Student's $t$-test.

Differences in serological protection rates between SENiEURS and Junieurs were analysed by the $\chi^{2}$ test. Serological protection rates of two consecutive years were analysed by the McNemar test.

\section{RESULTS}

\section{HI titre after single vaccination}

The prevaccination HI titres of SENIEURS and Juniturs were similar for most strains. However, prevaccination titres were significantly lower in the SEnieurs than in the Junieurs to the A/Taiwan/1/86 (H1N1) strain in 1991 and $1992(P=0.003$ and $P=0.001$, respectively, ANOVA) and the B/Yamagata/ $16 / 88$ strain in $1992(P=0.046$, ANOVA) (Table 2).

Each year Junieur and SENIEUR subjects who were vaccinated for the first time showed a significant rise in HI titre 21 days after vaccination against all influenza strains contained in the vaccine $(P<0.001$ for all strains, paired Student's t-test) (Table 2).

Compared to the Junieurs, the Senieurs had significantly lower postvaccination $\mathrm{HI}$ titres against the $\mathrm{H} 1 \mathrm{~N} 1$ vaccine strain in all three years $(P<0.05$ for all years, ANCOVA). The postvaccination $\mathrm{HI}$ titres against the $\mathrm{H} 3 \mathrm{~N} 2$ vaccine strains were similar for the two age groups in all three years. The postvaccination titres against the influenza B strain components of the vaccine were significantly lower in the SENIEURS than in the Junieurs $(P<0.01$ for all strains, ANCOVA), with the exception of the $B / B e i j i n g / 1 / 87$ vaccine strain in 1990 for which there was no significant difference between the age groups (Table 2).

\section{HI titres after annually repeated vaccination}

Previously vaccinated Junieurs and Senieurs had significantly higher prevaccination titres than previously unvaccinated subjects $(P<0.01$ for all strains, Student's $t$-test). Previously vaccinated subjects showed a significant rise in the $\mathrm{HI}$ titre 21 days after revaccination against the influenza strains contained in the vaccine ( $P<0.001$ for all strains, paired Student's $t$-test) (Table 2).

After repeated vaccination pre- and postvaccination HI titres of SENIEURS against the HINI vaccine component (A/Taiwan/1/86) remained lower than the HI titres of Junieurs $(P<0.05$, Student's $t$-test $)$, except for the postvaccination titre in 1992 where there was no difference between the age groups. In both age groups HI postvaccination titres against the $\mathrm{H} 1 \mathrm{~N} 1$ strain did not change after annually repeated vaccination in comparison with the postvaccination titre reached after one vaccination. Only SEnIEurs who entered the study in 1991 had significantly higher postvaccination $H I$ titres after the second vaccination in comparison with the first $(P<0.01$, paired Student's $t$-test), whereas after the third vaccination in 1993 the HI postvaccination titre decreased again significantly ( $P<0.01$, paired Student's $t$-test $)$ but remained higher than the postvaccination titre after one vaccination (Table 2).

During the study three different $\mathrm{H} 3 \mathrm{~N} 2$ components had been contained in the vaccine. After repeated vaccination the pre- and postvaccination titres against the $\mathrm{H} 3 \mathrm{~N} 2$ vaccine subtypes were largely comparable for the two age groups. Repeated vaccination with the $\mathrm{H} 3 \mathrm{~N} 2$ vaccine strains did not result in a decline of the postvaccination HI titre. The Senieurs who started in 1991 had a higher postvaccination titre against the vaccine strain $\mathrm{A} / \mathrm{Beijing} / 32 / 92$ in 1993 in comparison with the postvaccination titre against the yaccine strain A/Beijing/353/89 in $1992(P<0.05$, paired Student's t-test) (Table 2).

The postvaccination $\mathrm{HI}$ titres against the $\mathrm{B}$ strains $\mathrm{B} /$ Yamagata/16/88 and B/Panama/45/90 were lower in the SENIEURS after the first vaccination as compared to the Junieurs $(P<0.05$. Student's $t$-test $)$. After the second vaccination the postvaccination titres of the two age groups were not different anymore (Table 2). SENIEURS and JUNIEURS who started in 1990 had a significantly higher postvaccination titre after the second vaccination as compared to the first $(P<0.01$, paired Student's $t$-test). After the third vaccination in 1992 the Hl titre against the vaccine strain decreased again (Seniturs $P=0.0012$ and Juniturs $P=0.03$, paired Student's $t$-test) but remained higher than the titre after the first vaccination. For the SENIEURS, the fourth vaccination in 1993 resulted in a significant increase of the HI titre $(P=0.003$, paired Student's $t$-test) to a level comparable to the HI titre after the second vaccination. A diminished postvaccination titre in 1992 was not seen against the B/Panama/45/90 strain, which was the vaccine strain of the previous year (data not shown).

Senieurs who started in 1991 or 1992 also had an increase of postvaccination $\mathrm{HI}$ titre after the second vaccination as compared to the previous year $(P=0.02$ and $P<0.01$, respectively, paired Student's $t$-test). The HI postvaccination titre of the Senieurs from 1991 increased even more after a third vaccination in 1993 as compared to $1992(P=0.002$, paired Student's $t$-test). JUNIEURS who started in 1991 showed no significant changes in postvaccination titre after repeated vaccination. The $\mathrm{B} / \mathrm{Beijing} / 1 / 87$ strain had only been in the vaccine for two consecutive years. No differences between Junieurs and Senieurs were observed after repeated vaccination and there was no change in $\mathrm{HI}$ postvaccination titre level after the second vaccination (Table 2).

\section{Serological protection rates after annually repeated vaccination}

The serological protection rates for the $\mathrm{B}$ strains were increased after the sccond vaccination in both age groups in comparison with the first vaccination ( $P<0.04$, McNemar), for the other strains there was no change (Table 3). Similar to the pattern of HI postvaccination titres after repeated vaccination, the Senieurs from 1990 had a decreased serological protection rate to $\mathrm{B} /$ Yamagata/16/88 after the third vaccination in 1992 as compared to the serological protection rate to $\mathrm{B} / \mathrm{Panama} / 45 / 90$ in 1991 . but after the fourth vaccination in 1993 the serological protection rate to $\mathrm{B} / \mathrm{Panama} / 45 / 90$ again increased significantly $(P=0.001$, McNemar) (Table 3). A decrease of serological protection rate was not seen against the $\mathrm{B} /$ Panama/45/90 strain, which was the vaccine strain of the previous ycar (data not shown). 
Annually repeated influenza vaccination and HI titre in SENIEUR elderly: I.A. de Bruijn et al.

Serological protection rates against the HINI component of the vaccine were very low in both age groups, being $<50 \%$ for the SEnieurs and slightly $>50 \%$ for the JUnIIURS. The serological protection rates for the $\mathrm{H} 3 \mathrm{~N} 2$ and $\mathrm{B}$ components of the vaccine were higher for hoth age groups, being $60 \%$ or more with some exceptions. The numbers of serologically protected subjects after vaccination with the H1N1 and

Table $2 \mathrm{HI}$ titres after repeated vaccination

\begin{tabular}{|c|c|c|c|c|c|c|c|c|c|c|}
\hline \multirow[t]{2}{*}{$\mathrm{H} 1 \mathrm{~N} 1$} & \multirow[t]{2}{*}{$\mathrm{Age}^{a}$} & \multirow[t]{2}{*}{ Day $^{b}$} & \multicolumn{2}{|c|}{ A/Taiwan $1 / 86^{e}$} & \multicolumn{2}{|c|}{ A/Taiwan/1/86 } & \multicolumn{2}{|c|}{ A/Taiwan/1/86 } & \multicolumn{2}{|c|}{ A/Taiwan/1/186 } \\
\hline & & & $N^{\circ}$ & $1990^{d}$ & $N$ & 1991 & $N$ & 1992 & $N$ & 1993 \\
\hline & $\mathrm{S}$ & 0 & $57(1)$ & $6(5-6)$ & $40(2)$ & $21(13-33)^{\star}$ & $26(3)$ & $26(15-45)^{\star}$ & $12(4)$ & $22(12-40)$ \\
\hline & & 21 & & $44(28-69)^{\star}$ & & $47(31-72)$ & & $46(28-75)$ & & $37(19-72)$ \\
\hline & $J$ & 0 & $43(1)$ & $6(5-7)$ & $18(2)$ & $75(41-137)$ & $9(3)$ & $87(35-219)$ & & \\
\hline & & 21 & & $136(99-187)$ & & $118(82-168)$ & & $100(40-252)$ & & \\
\hline & $\mathrm{S}$ & 0 & & & $55(1)$ & $5(5-6)$ & $28(2)$ & $9(6-14)^{\star}$ & $17(3)$ & $20(10-38)$ \\
\hline & & 21 & & & & $18(13-27)^{\star}$ & & $47(30-74)^{\star \star}$ & & $31(16-58)^{* \star}$ \\
\hline & $J$ & 0 & & & $42(1)$ & $9(6-12)$ & $14(2)$ & $45(24-87)$ & & \\
\hline & & 21 & & & & $105(77-142)$ & & $73(42-126)$ & & \\
\hline & $\mathrm{S}$ & 0 & & & & & $26(1)$ & $6(5-7)$ & $13(2)$ & $25(9-67)$ \\
\hline & & 21 & & & & & & $57(28-117)^{*}$ & & $82(33-203)$ \\
\hline & $J$ & 0 & & & & & $38(1)$ & $15(9-25)$ & & \\
\hline & & 21 & & & & & & $206(149-284)$ & & \\
\hline \multirow[t]{14}{*}{$\mathrm{H} 3 \mathrm{~N} 2$} & Age & Day & \multicolumn{2}{|c|}{ A/Guizhou/54/89 } & \multicolumn{2}{|c|}{ A/Beijing/353/89 } & \multicolumn{2}{|c|}{ A/Beijing/353/89 } & \multicolumn{2}{|c|}{ A/Beijing/32/92 } \\
\hline & & & $N$ & 1990 & $N$ & 1991 & $N$ & 1992 & $N$ & 1993 \\
\hline & $\mathrm{S}$ & 0 & $57(1)$ & $16(11-23)$ & $40(2)$ & $114(77-170)$ & $26(3)$ & $156(103-236)$ & $12(4)$ & $43(18-102)$ \\
\hline & & 21 & & $328(227-474)$ & & $307(207-454)$ & & $273(186-400)$ & & $157(58-429)$ \\
\hline & J & 0 & $43(1)$ & $21(14-32)$ & $18(2)$ & $68(43-106)$ & $9(3)$ & $156(94-258)$ & & \\
\hline & & 21 & & $246(187-324)$ & & $328(192-562)$ & & $196(109-353)$ & & \\
\hline & $\mathrm{S}$ & & & & $55(1)$ & $8(6-11)$ & $28(2)$ & $67(37-125)^{\star}$ & $17(3)$ & $28(14-59)$ \\
\hline & & 21 & & & & $117(67-206)$ & & $308(203-465)$ & & $624(322-1211)^{\star \star}$ \\
\hline & J & 0 & & & $42(1)$ & $11(8-17)$ & $14(2)$ & $209(92-478)$ & & \\
\hline & & 21 & & & & $261(176-386)$ & & $248(107-575)$ & & \\
\hline & $\mathrm{S}$ & 0 & & & & & $26(1)$ & $9(7-13)$ & $13(2)$ & $18(8-39)$ \\
\hline & & 21 & & & & & & $186(84-411)$ & & $185(80-425)$ \\
\hline & $J$ & 0 & & & & & $38(1)$ & $14(9-22)$ & & \\
\hline & & 21 & & & & & & $276(169-452)$ & & \\
\hline \multirow[t]{14}{*}{ B1 } & Age & Day & \multicolumn{2}{|c|}{ B/Yamagata/16/88 } & \multicolumn{2}{|c|}{ B/Panama/45/90 } & \multicolumn{2}{|c|}{$\mathrm{B} /$ Yamagata/16/88 } & \multicolumn{2}{|c|}{ B/Panama/45/90 } \\
\hline & & & $N$ & 1990 & $N$ & 1991 & $N$ & 1992 & $N$ & 1993 \\
\hline & $\mathrm{S}$ & 0 & $57(1)$ & $6(5-8)$ & $40(2)$ & $96(60-151)^{\star}$ & $26(3)$ & $122(77-195)$ & $12(4)$ & $230(129-410)$ \\
\hline & & 21 & & $82(58-117)^{\star}$ & & $494(346-706)^{\star \star}$ & & $315(204-485)^{\star \star}$ & & $626(341-1149)^{\star \star}$ \\
\hline & $J$ & 0 & $43(1)$ & $9(6-12)$ & $18(2)$ & $291(156-543)$ & $9(3)$ & $218(106-448)$ & & \\
\hline & & 21 & & $232(158-339)$ & & $872(552-1378)^{\star \star}$ & & $371(236-581)^{\star \star}$ & & \\
\hline & $\mathrm{S}$ & 0 & & & $55(1)$ & $16(11-22)$ & $28(2)$ & $15(9-25)$ & $17(3)$ & $167(68-407)$ \\
\hline & & 21 & & & & $152(94-244)^{\star}$ & & $333(194-574)^{\star \star}$ & & $634(336-1200)^{\star \star}$ \\
\hline & $\mathrm{J}$ & 0 & & & $42(1)$ & $18(11-29)$ & $14(2)$ & $145(91-230)$ & & \\
\hline & & 21 & & & & $640(460-889)$ & & $462(303-703)$ & & \\
\hline & $S$ & 0 & & & & & $26(1)$ & $6(5-7)$ & $13(2)$ & $82(27-255)$ \\
\hline & & 21 & & & & & & $38(20-73)^{\star}$ & & $1413(682-2924)^{\star \star}$ \\
\hline & $J$ & 0 & & & & & $38(1)$ & $9(6-13)$ & & \\
\hline & & 21 & & & & & & $287(160-513)$ & & \\
\hline \multirow[t]{9}{*}{$\mathrm{B} 2$} & Age & Day & B/Beijir & $/ 1 / 87$ & B/Beiji & $/ 1 / 87$ & & & & \\
\hline & & & $N$ & 1990 & $N$ & 1991 & & & & \\
\hline & $S$ & $\begin{array}{r}0 \\
21\end{array}$ & 57 (1) & $\begin{array}{c}14(9-20) \\
177(116-268)\end{array}$ & $40(2)$ & $\begin{array}{c}75(47-120) \\
252(164-386)\end{array}$ & & & & \\
\hline & $J$ & 0 & $43(1)$ & $20(12-34)$ & $18(2)$ & $144(66-312)$ & & & & \\
\hline & & 21 & & $290(203-415)$ & & $366(238-562)$ & & & & \\
\hline & $\mathrm{S}$ & 0 & & & $55(1)$ & $27(17-44)$ & & & & \\
\hline & & 21 & & & & $233(150-361)^{\star}$ & & & & \\
\hline & $J$ & 0 & & & $42(1)$ & $22(13-35)$ & & & & \\
\hline & & .1 & & & & $657(400-1080)$ & & & & \\
\hline
\end{tabular}

Chronological listing of $\mathrm{HI}$ titres. Rows from left to right show cohorts starting in 1990,1991 or 1992 respectively. Numbers of subjects decrease as a result of loss to follow up. In 1993 only SENIEURS were revaccinated

${ }^{a} \mathrm{~S}$, SENIEURS; J, JuniEuRs

${ }^{\circ}$ Day $0=$ prevaccination titre; day 21 = postvaccination titre

Number of subjects (number of vaccinations received)

Year of vaccination

- Vaccine strain

Pre- and postvaccination HI titres GMT (95\% confidence interval): ${ }^{\star} P<0.05$; Student's $t$-test between titres of SENIEURS and JunIEUAS; $\star \star P<0.05$; paired $t$-test between current $\mathrm{HI}$ postvaccination titre and $\mathrm{HI}$ postvaccination titre in the previous year. Subjects due to loss to follow up were not considered in this analysis 
Annually repeated influenza vaccination and HI titre in SENIEUR elderly: I.A. de Bruijn et al.

Table 3 Serological protection rates after repeated vaccination

\begin{tabular}{|c|c|c|c|c|c|c|c|c|c|c|}
\hline \multirow[t]{2}{*}{ N1N1 } & \multirow[t]{2}{*}{$\mathrm{Age}^{a}$} & \multirow[t]{2}{*}{$\mathrm{Day}^{\mathrm{b}}$} & \multicolumn{2}{|c|}{ A/Taiwan $/ 1 / 86^{d}$} & \multicolumn{2}{|c|}{ A/Taiwan/1/86 } & \multicolumn{2}{|c|}{ A/Taiwan/1/86 } & \multicolumn{2}{|c|}{ A/Taiwan/1/86 } \\
\hline & & & $N^{c}$ & $1990^{\circ}$ & $N$ & 1991 & $N$ & 1992 & $N$ & 1993 \\
\hline & $S$ & 0 & $57(1)$ & 2 & $40(2)$ & 15 & $26(3)$ & 19 & $12(4)$ & 0 \\
\hline & & 21 & & $28^{*}$ & & 30 & & $23^{\star}$ & & 17 \\
\hline & J & 0 & $43(1)$ & 0 & $18(2)$ & 56 & $9(3)$ & 56 & & \\
\hline & & 21 & & 63 & & 56 & & 67 & & \\
\hline & $S$ & 0 & & & 55 (1) & 0 & $28(2)$ & 0 & $17(3)$ & 12 \\
\hline & & 21 & & & & $13^{\star}$ & & 32 & & 24 \\
\hline & J & 0 & & & $42(1)$ & 2 & $14(2)$ & 29 & & \\
\hline & & 21 & & & & 55 & & 50 & & \\
\hline & $s$ & 0 & & & & & $26(1)$ & 0 & $13(2)$ & 15 \\
\hline & & 21 & & & & & & $31^{*}$ & & 46 \\
\hline & $J$ & 0 & & & & & $38(1)$ & 21 & & \\
\hline & & 21 & & & & & & 79 & & \\
\hline \multirow[t]{13}{*}{$\mathrm{H} 3 \mathrm{~N} 2$} & Age & Day & \multicolumn{2}{|c|}{ A/Guizhou/54/89 } & \multicolumn{2}{|c|}{ A/Beijing/353/89 } & \multicolumn{2}{|c|}{ A/Beijing/353/89 } & \multicolumn{2}{|c|}{ A/Beijing/32/92 } \\
\hline & & & $N$ & 1990 & $N$ & 1991 & $N$ & 1992 & $N$ & 1993 \\
\hline & $S$ & $\begin{array}{r}21 \\
0\end{array}$ & $57(1)$ & $\begin{array}{l}12 \\
88\end{array}$ & $40(2)$ & $\begin{array}{l}45 \\
75\end{array}$ & $26(3)$ & $\begin{array}{l}73 \\
92\end{array}$ & $12(4)$ & $\begin{array}{l}25 \\
67\end{array}$ \\
\hline & $J$ & 21 & $43(1)$ & 14 & $18(2)$ & 33 & $9(3)$ & 78 & & \\
\hline & & 0 & & 81 & & 83 & & 89 & & \\
\hline & $S$ & 21 & & & $55(1)$ & 2 & $28(2)$ & 36 & $17(3)$ & 24 \\
\hline & & 0 & & & & $58^{\star}$ & & $89^{\star \star *}$ & & 94 \\
\hline & $J$ & 21 & & & $42(1)$ & 10 & $14(2)$ & 71 & & \\
\hline & & 0 & & & & 79 & & 79 & & \\
\hline & $S$ & 21 & & & & & $26(1)$ & 0 & $13(2)$ & 15 \\
\hline & & 0 & & & & & & 58 & & 69 \\
\hline & J & 0 & & & & & 38 (1) & 13 & & \\
\hline & & 21 & & & & & & 76 & & \\
\hline \multirow[t]{14}{*}{ B1 } & Age & Day & \multicolumn{2}{|c|}{$\mathrm{B} /$ Yamagata/16/88 } & \multicolumn{2}{|c|}{ B/Panama/45/90 } & \multicolumn{2}{|c|}{$\mathrm{B} /$ Yamagata/16/88 } & \multicolumn{2}{|c|}{ B/Panama/45/90 } \\
\hline & & & $N$ & 1990 & $N$ & 1991 & $N$ & 1992 & $N$ & 1993 \\
\hline & $S$ & 0 & $57(1)$ & 0 & $42(2)$ & 35 & $26(3)$ & 27 & $12(4)$ & 58 \\
\hline & & 21 & & $30^{*}$ & & $85^{\star \star}$ & & $62^{\star *}$ & & 92 \\
\hline & J & 0 & $43(1)$ & 0 & $18(2)$ & 61 & $9(3)$ & 56 & & \\
\hline & & 21 & & 58 & & $94^{\star \star}$ & & 89 & & \\
\hline & $S$ & 0 & & & $55(1)$ & 4 & $28(2)$ & 4 & $17(3)$ & 47 \\
\hline & & 21 & & & & $45^{\star}$ & & $64^{*}$ & & 82 \\
\hline & J & 0 & & & $42(1)$ & 12 & $14(2)$ & 36 & & \\
\hline & & 21 & & & & 86 & & 93 & & \\
\hline & $S$ & 0 & & & & & $26(1)$ & 0 & $13(2)$ & 31 \\
\hline & & 21 & & & & & & $15^{\star}$ & & $92^{\star \star}$ \\
\hline & $\mathrm{J}$ & 0 & & & & & $38(1)$ & 0 & & \\
\hline & & 21 & & & & & & 68 & & \\
\hline \multirow[t]{9}{*}{ B2 } & Age & Day & \multicolumn{2}{|c|}{ B/Beijing/1/87 } & B/Beijin & & & & & \\
\hline & & & $N$ & 1990 & $N$ & 1991 & & & & \\
\hline & $S$ & 0 & $57(1)$ & 7 & $40(2)$ & 28 & & & & \\
\hline & & 21 & & $51 *$ & & 60 & & & & \\
\hline & J & 0 & $43(1)$ & 14 & $18(2)$ & 61 & & & & \\
\hline & $S$ & $\begin{array}{r}21 \\
0\end{array}$ & & 72 & & 83 & & & & \\
\hline & & $\begin{array}{r}0 \\
21\end{array}$ & & & $55(1)$ & 11 & & & & \\
\hline & $J$ & 0 & & & $42(1)$ & $\begin{array}{c}51^{\star} \\
7\end{array}$ & & & & \\
\hline & & 21 & & & & 83 & & & & \\
\hline
\end{tabular}

Chronological listing of serological protection rates. Rows from left to right show cohorts starting in 1990, 1991 or 1992 respectively. Numbers of subjects decrease as a result of loss to follow up. In 1993 only SENIEURS were revaccinated

${ }^{a} \mathrm{~S}$, Senieurs; J, Junieurs

${ }^{D}$ Day $0=$ prevaccination titre; day 21 = postvaccination titre

${ }^{c}$ Number of subjects (number of vaccinations received)

"Vaccine strain

Year of vaccination

Pre- and postvaccination serological protection rates. Numbers are percentages of subjects with protective $\mathrm{HI}$ titre (HI $>100$ for influenza A strains; $\mathrm{HI}>200$ for influenza B strains)

${ }^{\star} P<0.02 ; \gamma^{2}$ test between serological protection rates of SENIEURS and JuNIEURS

$\star \star P<0.05 ;$ McNemar test between current postvaccination serological protection rate and postvaccination serological protection rate in the previous year. Subjects due to loss to follow up were not considered in this analysis 
B components show some differences between Senieurs and Junieurs. In most cases the Junieurs reached higher serological protection rates than the Senieurs (Table 3).

\section{DĨSCUSSION}

When SENIEUR young and elderly are vaccinated repeatedly with influenza vaccine no decline in antibody formation or serological protection rate can be observed in this study. These data are in agreement with data published concerning annually repeated influenza vaccination in young or middle-aged persons ${ }^{5.7}$. The increase in the postvaccination $\mathrm{HI}$ titre against the influenza $B$ strains as a result of annually repeated vaccination was also found by Howells et al.".

However, the Senieurs vaccinated for the first time in 1991 show some changes in the postvaccination titres against the H1N1 strain reached after the second and third vaccination. The postvaccination titre rises significantly after the second vaccination in comparison with the first and declines again significantly after the third vaccination but remains higher than the titre after the first vaccination. The rise after the second vaccination could be explained in part by a poor antigenicity of the vaccine in 1991, as we found lower $\mathrm{HI}$ responses after vaccination in persons entering in 1991 than in those who were vaccinated in 1990 or 1992 for the first time. This HI titre rise in the Seniturs from 1991 after vaccination in 1992 was also seen for the H3N2 strain A/Bcijing/353/89 though this was not statistically significant. However, as the titre against the H1N1 component decreases again after the third vaccination it is more likely that the fluctuations seen in this group are a result of group related differences.

The antibody formation after vaccination in 1992 with $\mathrm{B} /$ Yamagata/16/88 seems to be lower than the $\mathrm{HI}$ titre against $\mathrm{B} / \mathrm{Panama} / 45 / 90$ in the previous year. However, the subjects still have a high amount of antibody in 1992 to the vaccine strain of 1991. This lower antibody measurement against B/Yamagata/16/88 could be explained by a different avidity of B/Panama/45/90 in the $\mathrm{HI}$ test.

The HI titre reached after vaccination was extrapolated to a measure of serological protection. The diminished protection after repeated vaccination found by Hoskins in schoolboys" was not found in the Junieurs and Senieurs of this study. Moreover, for the $B$ strains the serological protection rates after the second vaccination were higher than after the first vaccination. The serological protection rates were calculated for the antibody production against the vaccine strains, whereas the antibody titres and serological protection rates to the epidemic virus strains were not determined. Possibly the serological protection rates given here might differ from the actual protection against a challengc with epidemic virusses.

Longitudinal observation of postvaccination titres against influenza vaccine strains presents some difficulties. Because the composition of the vaccine changes every year and because of possible differences in sensitivity of these different strains in the HI test a comparison from one year to the other must be made with caution. When the vaccine strain changed from one year to another, in the case of the H3N2 and B components, the antibody response to the vaccine component of the previous year was also measured (data not shown). It appeared that this heterologous response was sometimes even better than the response to the vaccine strain. This anamnestic phenomenon has been described before ${ }^{7-31}$ and has to be taken into account when evaluating the response after repeated vaccination.

When considering pre- and postvaceination HI titres in healthy subjects who had not been vaccinated against influenza for at least 2 years, several differences between Junieurs and Senieurs occurred in the quantitative antibody formation against influenza haemagglutinin. The finding that elderly showed a lower immune response to the A/Taiwan/1/86 ( H1N1) strain has been reported earlier ${ }^{5,31,32}$ and our data concerning the differences in the postvaccination HI titre are in agreement with data from McElhancy et $a l . "$ "They found lower postvaccination $\mathrm{Hl}$ antibody levels in 1990) and 1991 against the 1 IIN 1 strain $A / T a i w a n / 1 / 86$ and the $B$ strains $B / Y$ amagata/16/88 and $B / P a n a m a / 45 / 90$ in SENiEuR elderly and young subjects of the same age groups as ours with the same vaccine strains as in our study in 1990 and 1991. They also found no difference in postvaccination $\mathrm{HI}$ titres against the H3N2 strains between the two age groups.

A diminished $\mathrm{HI}$ antibody response in the clderly has been reported before in other studies, but also equal or even higher antibody responses have been reported ${ }^{23}$. With regard to the results of this study we may conclude that in the absence of biases like differences in the prevaccination titre, underlying disease and use of drugs, there is an age-related, vaccine strain-dependent difference in $\mathrm{HI}$ antibody formation after influenza vaccination.

It was suggested that the phenomenon of original antigenic sin may explain age-related differences in the antibody responses between the $\mathrm{H} 1 \mathrm{~N} 1$ and $\mathrm{H} 3 \mathrm{~N} 2$ vaccine strains ${ }^{31,33}$. The SENIEURs would be optimally primed for the strains of the $\mathrm{H} 1 \mathrm{Nl}$ subtype that circulated during their childhood, whereas the JunIIURs were primed for H1-strains closer related to the current H1Nl strains. This could result in an age-related altered response to later influenza strains of the Hl subtype ${ }^{23}$. In contrast, the Stenileurs would not have been exposed to the H3N2 subtype until the late sixties, resulting in an equal exposure to viruses of the H3N2 subtype for both age groups.

\section{CONCLUSIONS}

There was no decline of $\mathrm{HI}$ antibody to the vaccinc strains after annually repeated vaccination in SENIEURS and Junieurs. Moreover, for the B strains a second vaccination resulted in an even higher postvaccination titre against the vaccine strain. Also the serological protection rates after annually repcated vaccination showed no decline. Thus annual influenza vaccination has proved to be effective in maintaining an adequate, protective $\mathrm{HI}$ antibody titre against the vaccine strains.

The results of this study demonstrate an association between high age and a declined responsiveness to some influenza vaccine strains, but whether this is a true senescence phenomenon requires further investigation, as we did not see this decrease for all vaccinc strains. 


\section{ACKNOWLEDGEMENTS}

Expert technical assistance was given by Ruud van Beck and colleagues of the Netherlands Influenza Centre Rotterdam.

\section{REFERENCES}

1 Nicholson, K.G., Snacken, R. and Palache, A.M. Influenza immunization policies in Europe and the United States. Vaccine 1995, 13, 365-369.

2 Barker, W.H. and Mullooly, J.P. Influenza vaccination of elderly persons: reduction in pneumonia an influenza hospitalizations and deaths. J. Am. Med. Assoc. 1980, 244, 2547-2549

3 Patriarca, P.A., Weber, J.A. and Parker, R.A. et al. Efficacy of influenza vaccine in nursing homes: reduction in illness and complications during an influenza $A(H 3 N 2)$ epidemic. J. Am. Med. Assoc. 1985, 253, 1136-1139.

4 Nichol, K.L., Margolis, K.L., Wuorenma, J. and Von Sternberg, T.L. The efficacy and cost effectiveness of vaccination against influenza among elderly persons living in the community. $N$. Engl. J. Med. 1994, 331, 778-784.

5 Pyhälä, R., Kumpulainen, V., Alanko, S. and Forsten, T. HI antibody kinetics in adult volunteers immunized repeatedly with inactivated trivalent influenza vaccine in 1990-1992. Vaccine 1994, 12, 947-952.

6 Hoskins, T.W., Davies, J.R., Smith, A.J., Miller, C.L. and Allchin, A. Assessment of inactivated influenza-A vaccine after three outbreaks of influenza-A at Christs's Hospital. Lancet $1979, \mathrm{i}, 33-35$.

7 Keitel, W.A., Cate, T.R. and Couch, R.B. Efficacy of sequential annual vaccination with inactivated influenza virus vaccine. Am. J. Epidemiol. 1988, 127, 353-364.

8 Gross, P.A., Quinnan, G.V., Weksler, M.E., Setia, U. and Douglas, R.G. Relation of chronic disease and immune response to influenza vaccine in the elderly. Vaccine 1989,7 , 303-308.

9 Howells, C.H.L., Vesselinova-Jenkins, C.K., Evans, A.D. and James, J. Influenza vaccination and mortality from bronchopneumonia in the elderly. Lancet 1975, i, 381-383.

to Glathe, H., Bigl, S. and Grosche, A. Comparison of humoral immune responses to trivalent influenza split vaccine in young, middle aged and elderly people. Vaccine 1993, 11, $702-705$.

11 Hobson, D., Baker, F.A. and Curry, R.L. Effect of influenza vaccines in stimulating antibody in volunteers with prior immunity. Lancet 1973. 155-156

12 Govaert, T.M.E., Sprenger, M.J.W., Dinanl, G.J., Aretz, K. Masurel, N. and Knottnerus, J.A. Immune response to influenza vaccination in elderly people. A randomized double blind placebo controlled trial. Vaccine 1994, 12, 1185-1189.

13 Gruber, W.C., Campbell, P.W., Thompson, J.M., Reed, G.W., Roberts, B. and Wright, P.F. Comparison of live attenuated and inactivated influenza vaccines in cystic fibrosis patients and their families: results of a 3 -year study. J. Infect. Dis. 1994, 169, $241-247$

14 Powers, R.D., Hayden, F.G., Samuelson, J. and Gwaltney Jr, J.M. Immune response of adults to sequential influenza vaccination. J. Med. Virol. 1984, 14, 169-175.

15 Sprenger, M.J.W., Mulder, P.G.H., Beyer, W.E.P., van Strik, R. and Masurel, N. Impact of influenza on mortality in relation to age and underlying disease, 1967-1989. Int. J. Epidemiol. $1993,22,334-340$.
16 Barker, W.H. and Mullooly, J.P. Impact of epidemic type A influenza in a defined adult population. $A m$. J. Epidemiol. $1980,112,798813$

17 Hall, W.N., Goodman, R.A., Noble, G.R., Kendal, A.P. and Steece, R.S. An outbreak of influenza $B$ in an elderly population. J. Infect. Dis. 1981, 144, 297

18 Barker, W.H. and Mullooly, J.P. Pneumonia and influenza deaths during epidemics: implications for prevention. Arch. Intern. Med. 1982, 142, 85-89.

19 Remarque, E.J., Cools, H.J.M., Boere, T.J., van der Klis, R.J. Masurel, N. and Ligthart, G.J. Functional disability and antibody response to influenza vaccine in elderly patients in a Dutch nursing home. Br. Med. J. 1996, 312, 1015-1-15.

20 Wade, A.W., Green-Johnson, J. and Szewczuk, M.R. Functional changes in systemic and mucosal lymphocyte repertoires with age: an update review. Aging: Immunol. Infect. Dis. 1988, 1, 65-97.

21 Remarque, E.J., van Beek, W.C.A. and Ligthart, G.J. et al. improvement of the immunoglobulin subclass response to influenza vaccine in elderly nursing-home residents by the use of high-dose vaccines. Vaccine 1993, 11, 649-654.

22 Ligthart, G.J., Corberand, J.X. and Hart, R. et af. Admission criteria for immunogerontological studies in man: the SENIEUR protocol. Mech. Ageing Dev. 1984, 28, 47-55.

23 Beyer, W.E.P., Palache, A.M., Baljet, M. and Masurel, N. Antibody induction by influenza vaccines in the elderly: a review of the literature. Vaccine 1989, 7, 385-394

24 Masurel, N., Ophof, P. and de Jong, P. Antibody respons to Immunization with influenza A/USSR/77 ( $\mathrm{H} 1 \mathrm{~N} 1)$ virus in young individuals primed or unprimed for A/New Jersey/76 (H1N1) virus. J. Hyg. Camb. 1981, 87, 201-209.

25 Berlin, B.S., McQueen, J.L., Minuse, E. and Davenport, F.M. A method for increasing the sensitivity of the haemagglutination-inhibition test with equine influenza virus. Virology 1963, 21, 665-667.

26 Beyer, W.E.P., Teunissen, M.W.E., Diepersloot, R.J.A. and Masurel, N. Immunogenicity and reactogenicity of two doses of a trivalent influenza split vaccine. An open randomized study in healthy, unprotected, adult volunteers. J. Drugther. Res. $1986,11,369$

27 Virelizier, J., Allison, A.C. and Schild, G.C. Antibody responses to antigenic determinants of influenza virus haemagglutinin. II. Original antigenic sin: a bone marrowderived lymphocyte memory phenomenon modulated by thymus derived lymphocytes. J. Exp. Med. 1974, 140, $1571-1578$.

28 Francis. T.J. On the doctrine of the original antigenic $\sin$. Proc. Am. Phil. Soc. 1960, 104, 572-578.

29 Webster, R.G., Kasel, J.A., Couch, R.B. and Laver, W.G. Influenza subunit vaccines 11 . Immunogenicity and original antigenic sin in humans. J. Infect. Dis. 1976, 134, 48-58.

30 McElhaney, J.E., Meneilly, G.S., Lechelt, K.E., Beattie, B.L. and Bleackley, R.C. Antibody response to whole-virus and split-virus influenza vaccines in successful ageing. Vaccine 1993, 11, 1055-1060.

31 Powers, D.C. and Belshe, R.B. Effect of age on cytotoxic T lymphocyte memory as well as serum and local antibody responses elicited by inactivated influenza virus vaccine. $J$. Infect. Dis. 1993, 167, 584-592.

32 Palache, A.M., Beyer, W.E.P. and Sprenger, M.J.W. et al. Antibody response after influenza immunization with various vaccine doses: a double-blind, placebo-controlled, multicentre, dose-response study in elderly nursing-home residents and young volunteers. Vaccine 1993, 11, 3-9.

33 Powers, D.C. and Belshe, R.B. Vaccine-induced antibodies to heterologous influenza A HINI viruses: effects of aging and 'original antigenic sin'. J. Infect. Dis. 1994, 169, 1125-1129. 